\title{
Use and misuse of the Edinburgh Postnatal Depression Scale (EPDS): a ten point 'survival analysis'
}

\author{
John Cox ${ }^{1}$
}

Published online: 4 November 2017

(C) Springer-Verlag GmbH Austria 2017

\section{Introduction}

The EPDS was developed over thirty years ago by JLC (transcultural/social psychiatrist), Jenifer Holden (psychologist and health visitor) and Ruth Sagovsky (part-time psychiatry trainee). Each of us knew at first hand about the mood disturbances that accompany childbirth. Each of us had clinical experience of the impact of perinatal depression on the family — and each of us had recognised that any screening scale must be acceptable to the mothers themselves and to the health professionals who administer it.

It is for these reasons that the EPDS is widely used in international clinical and research work, has been translated into over sixty languages, validated in most regions of the world and is recommended as a useful adjunct in the UK to the assessment of perinatal women.

Four of the papers published in this issue of the Journal illustrate the usefulness of the EPDS in an RCT of the effect of Motivational Interviewing on help seeking behaviour in Australia (Holt et al 2017), the caution required when interpreting cut off scores across cultural and language boundaries (Chiu et al. 2017), as well as the need for scholarly debate about its cut off scores - especially in the first week post-partum, when validity and reliability are uncertain (Matthey 2017, Merry 2017).

Sometimes the use of the EPDS in community and perinatal services, as well as in some published research, can be suboptimal - and occasionally dangerously misleading. It is for these reasons that a Ten Point Supplement to the Manual (Cox et al. 2014) was developed (Table 1).

John Cox

John6.cox@gmail.com

1 Keele University, Staffordshire ST5 5BG, UK
Table 1 Optimal use of the EPDS: ten-point supplement to the published Manual (Cox et al. 2014)

When using the EPDS for clinical or research purposes, give very careful consideration to the following ten points:

1. Be careful to check the validity of the scale for the population of mothers completing the EPDS.

2. Establish its sensitivity, specificity, positive predictive value and optimal cut off points for the purpose of your clinical or research work.

3. Remember that the EPDS is NOT diagnostic of mental disorder. A 'high score' indicates that depressive symptoms are present - but not their duration or intensity. The EPDS is not a test for PND or for an anxiety disorder.

4. When using the EPDS in other languages, make sure that the back translation is satisfactory and that there is also evidence of satisfactory Face, Semantic, Conceptual and Technical validity.

5. Remember that the EPDS is NOT a check list of common symptoms of perinatal depression. It deliberately omitted somatic symptoms and items concerned with the mother-infant relationship.

6. Remember that the EPDS was validated, piloted and evaluated in Edinburgh by a clinically informed research team to assist with the detection of postnatal and antenatal depression in community clinics.

7. When using the EPDS as an aid to assessment, or in universal or targeted screening, remember that its administration must be supervised by a trained health professional with access to mental health services.

8. When used to assess a mother in the community, the practitioner should discuss the responses with her, listen to her story, ascertain whether clinical depression or another mental disorder is present — and consider referral and/or further listening visits.

9. The risk of developing a postnatal psychosis should always be assessed. The EPDS does NOT screen for bipolar disorder.

10. The EPDS was developed in Edinburgh by John Cox, Jenifer Holden and Ruth Sagovsky over thirty years ago. Please read the recent EPDS Manual (Cox et al. 2014) so that the scale continues to be used optimally in research and clinical work. 
Considering these recommendations will assist both clinicians and researchers at the outset of their work and (when supplemented by wider reading) will reduce the possibility of the EPDS being misused.

\section{Epilogue}

At first sight, it is a paradox that a self-report depression scale with a clinical pedigree has no items that tap directly the family relationships, is in no sense a check list of depressive symptoms, and converts a mood state into a numerical score. Yet, it is largely because of these deliberate omissions and its face and criterion validity that the EPDS has continued to be used widely thirty years after it was first published (Cox et al. 1987).

Elliott (1994), who with Jennifer Holden was a pioneer of Training the Trainers programmes, has aptly described the EPDS as 'not a magic wand'. It is a useful adjunct to a clinical interview, a first stage screening instrument and also a conversation opener for a primary care worker trained in its use.

Within the context of a relationship based and existential biopsychosocial approach to research, public health and service delivery, the EPDS may remain useful for several decades to come.

\section{Compliance with Ethical Standards}

Conflict of Interest John Cox declares that he has no conflict of interest.

\section{References}

Chiu YHM, Sheffield PE, Hsu HHL. et al. (2017) Subconstructs of the Edinburgh Postnatal Depression Scale in a multi-ethnic inner-city population in the U.S.. Arch Womens Ment Health. https://doi.org/ 10.1007/s00737-017-0765-2

Cox J, Holden J, Sagovsky R (1987) Detection of post-natal depression: development of the ten item Edinburgh Postnatal Depression Scale. Br J Psychiatry 150:782-786

Cox J Holden J and Henshaw C (2014) Perinatal Mental health: the Edinburgh Postnatal Depression Scale ( EPDS) Manual Royal College of Psychiatrists Publications London

Elliott S (1994) The Edinburgh Post-natal depression Scale in primary care: comparison of models developed in health visiting. In Perinatal Psychiatry: use and misuse of the Edinburgh Post-natal Depression Scale (eds Cox J and Holden J) Gaskell London

Holt C, Milgrom J, Gemmill AW (2017) Improving help-seeking for postnatal depression and anxiety: a cluster randomised controlled trial of motivational interviewing. Arch Womens Ment Health. https://doi.org/10.1007/s00737-017-0767-0

Matthey S, (2017) Does an early postpartum Edinburgh Postnatal Depression Scale (EPDS) really detect the majority of women with elevated EPDS scores at 16-weeks postpartum? Arch Womens Ment Health. https://doi.org/10.1007/s00737-017-0763-4

Merry L, (2017) Missed the take-home message. Arch Womens Ment Health. https://doi.org/10.1007/s00737-017-0764-3 